\title{
A systematic review of association rules in project management: opportunities for hybrid models
}

\author{
Michael Jordan Bianchi ${ }^{a}$ (D), Daniel Capaldo Amaral ${ }^{a}$ \\ - Escola de Engenharia de São Carlos, Universidade de São Paulo - USP, São Carlos, SP, Brasil \\ e-mails: michael_bianchi@usp.br; amaral@sc.usp.br
}

\begin{abstract}
It is known that significant amounts of data are collected and stored in project management environments due to the use of digital communication and data storage technologies. At the same time, there is the challenge of managing increasingly complex projects in environments that require significant levels of agility. One way to deal with this problem is through hybrid management models. Could data mining techniques assist in the development of hybrid models, allowing organizations to deal with the complexity of their projects? This study identified the state of the art on the use of association rules in project management, identifying opportunities for research. Among data mining techniques, we prioritize association rules, which aim to find interesting patterns in large data sets. Through a systematic literature review, ten studies were found proposing the use of association rules in project management. As a result, we propose potential solutions using data mining to deal with complexity in the context of hybrid project management. The study aims to contribute to the advancement of project management literature and to shows new research opportunities in the area.
\end{abstract}

Keywords: data mining, association rules, hybrid models, project management.

\section{Introduction}

The complex projects management in dynamic environments will be the hallmark of the industry 4.0 and innovation through ecosystems (Iansiti \& Lakhani, 2014). The result is increasingly complex projects due to technological changes, diversity of actors, business models, and business environment (San Cristóbal et al., 2019). This complexity is related to several factors such as the number of variables/components and the interaction between them (Luo et al., 2017).

Several studies have explored complexity in projects. For example, Floricel et al. (2018) proposed a framework for describing the consequences of complexity for project form and evolution. The authors identified four types of complexity and outlined strategies for dealing with different project contexts: iteration, options, agility, and modularity. According to authors the agility is a survival strategy for complex projects (Floricel et al., 2018).

We are facing a trade-off in which increasingly complex environments will require more agility. Imani et al. (2017) defend the combination of management practices as an alternative to deal with this challenge, since it has the capacity to be more adaptable to the inherent needs of the business environment. This management strategy has been called hybrid models, one of the most discussed topics in research on agility and innovation projects (Adelakun et al., 2017; Ciric et al., 2018).

Organizations rarely use "pure" methods and the use of hybrid models is a potential solution to deal with the current business environment. Several authors have proposed hybrid models in recent years, such as Cooper (2014), Fitzgerald et al. (2013), Sommer et al. (2015), Conforto \& Amaral (2016), Alqudah \& Razali (2016), and Hobbs \& Petit (2017). However, these models were built by specialists within a specific context and environments, and for certain types of projects and industries, which makes it difficult to use for other contexts. The complexity increases since each organization have its characteristics, different levels of innovation, product complexity, resources, customers, in addition to the high number of methods and practices available. One of the main challenges in the use of hybrid models is to develop skills and tools capable of dealing with the complexity and dynamism of the business environment in order to develop management solutions suited to the needs of each project.

The popularization and advances in technologies such as Big Data, connectivity, and real-time observations, make data mining a promising strategy to deal with problems of this nature. The application of data mining algorithms in project management can be feasible to discover patterns 
and knowledge from large amounts of data. This can assist organizations and professionals in developing hybrid models to the specific context of their projects. For example, the use of data mining may indicate that practice A or B, or a combination of practices, is more beneficial for the management of the project under development, based on past experience of similar projects and organizational factors.

One of the main techniques for identifying these patterns is the Association Rules (AR). We propose a systematic literature review on association rules in project management, in order to identify the state of the art on the topic and explore its potential to deal with the main problems related to the development and application of hybrid models. The paper also opens up new perspectives for the development of strategies, tools and methods to assess the conditions of the environment and the project, and assist professionals and organizations to develop better management solutions for their projects.

The rest of the paper is structured as follows. Section II provides the theoretical background. In Section III, we discuss the research method. The results and discussions are provided in Section IV. In Section V, the final conclusions and future research are presented.

\section{Theoretical background}

\subsection{Data mining and association rules}

The computerization of society, the collection and storage of information has evolved exponentially over the years. Engineering practices generate high volumes of information, whether related to your processes and operations, finance, people and marketing. This amount of data has required the use of appropriate techniques to discover valuable information and turn it into knowledge (Han et al., 2012). These facts culminated in data mining, which can be defined as the process of discovering interesting patterns and knowledge from large amounts of data, being applied in the most varied areas and sectors of the economy (Han et al., 2012).

Let's imagine a company with structured project management, which systematically extracts and stores information about all its projects (e.g. type, needs, teams, environment, practices, results). What types of patterns and information could be revealed from this database using data mining techniques? Is it possible to think of patterns of management practices according to the characteristics and environment of the project? This information could help these professionals in future projects? The answer to these questions can be valuable for organizations and the development of the project management area.

Association rules is a data mining technique used to identify frequent patterns. It is an unsupervised technique, that is, the correct answer is not provided to the system (labeled data), and the algorithm finds out for itself. The technique makes it possible to find interesting patterns (relationships, dependencies) in large sets of data items (Cios et al., 2007). This association between items can provide important information for the user. A classic example is shown below (Cios et al., 2007, p.291): “[...] major (x, Computer Engineering) AND takes_course (x, Advanced Data Analysis and Decision Making) $\Rightarrow$ level $(\mathrm{x}, \mathrm{PhD})[\mathrm{s}=1 \%, \mathrm{c}=75 \%] "$.

The left part is called the antecedent and the right part is consequent. This rule states that students graduated in Computer Engineering and who are taking Advanced Data Analysis and Decision Making are at the doctoral level, with $1 \%$ support and $75 \%$ confidence. This type of association is used for a wide range of purposes, such as designing product catalogs, planning store shelving layouts, DNA sequence analysis, web log analysis (click stream), and building recommendation systems (Houtsma \& Swami, 1995).

\subsection{Hybrid models in project management}

Hybrid models are being increasingly studied and used by different organizations. This interest is being driven by the need to deal with new market challenges, such as complexity and innovation, and different types of projects in the same organization. In these cases, the variety of interrelated factors, aligned with the uniqueness of each project, means that the use of pure management approaches (agile and waterfall) do not fully meet the needs of each case (Adelakun et al., 2017; Riesener et al., 2018; Ambler \& Lines, 2018).

The combination of agile and waterfall practices aims to balance predictability and anticipation with flexibility and adaptability, providing agility in complex environments. We will use the definition proposed by Conforto et al. (2015, p.10) that define hybrid models as:

The combination of principles, practices, techniques and tools from different approaches in a systematic process that aims to adapt management to the business context and specific type of projects. The goal is to maximize the performance of the project and product, provide a balance between predictability and flexibility, reduce risk and increase innovation, to deliver better business results and customer value.

There is a wide range of hybrid models proposed in the literature. A systematic literature review to identify these models can be consulted in Silva et al. (2019). The search was updated for the present study and the synthesis of this analysis can be seen in Table 1.

Despite the existence of these models, all of them have the limitation of being developed for a specific context, according to the particularities of the business, product characteristics, customer, market and specific technology. XPrince was proposed for different types of software, and 
IVMP2 for manufacturing. Even with the specificities, these proposals are presented as prescriptive models, and many organizations and professionals seek to use them as a solution for the management of their projects. In this context, Table 2 presents the main characteristics and problems related to the hybrid models available in the literature.

The main problems are related to the uniqueness of the projects, understanding the environment and selecting or adapting management practices for each case, from a wide variety of possibilities. This study seeks to explore the potential use of association rules to overcome these challenges related to the use of hybrid models.

\section{Method}

The study included a systematic literature review (SLR) about association rules, in order to verify the potential of data mining to assist project management, especially the use of hybrid models. The SLR method proposed by

Table 1. Hybrid models identified in the literature.

\begin{tabular}{|c|c|c|c|c|}
\hline Authors/year & Hybrid Model & $\begin{array}{c}\text { Combination of } \\
\text { approaches }\end{array}$ & Which methods/models encompass & Application area \\
\hline $\begin{array}{l}\text { (Nawrocki et al., } \\
\text { 2006) }\end{array}$ & XPrince & Agile + Waterfall & $\begin{array}{c}\text { Extreme Programming (XP), } \\
\text { PRINCE2 and Rational Unified } \\
\text { Process (RUP) }\end{array}$ & Software development \\
\hline $\begin{array}{l}\text { (Rahimian \& } \\
\text { Ramsin, 2008) }\end{array}$ & $\begin{array}{c}\text { Mobile Software } \\
\text { Development Methodology }\end{array}$ & Agile + Agile & $\begin{array}{c}\text { Adaptative Software Development } \\
\text { (ASD) and New Product } \\
\text { Development (NPD) }\end{array}$ & $\begin{array}{c}\text { Mobile software } \\
\text { development }\end{array}$ \\
\hline (Cho, 2009) & $\begin{array}{c}\text { Hybrid Software } \\
\text { Development Method for } \\
\text { Large-Scale Projects }\end{array}$ & Agile + Waterfall & $\begin{array}{l}\text { Rational Unified Process (RUP) and } \\
\text { SCRUM }\end{array}$ & $\begin{array}{l}\text { Large and complex } \\
\text { projects }\end{array}$ \\
\hline $\begin{array}{l}\text { (Zaki \& Moawad, } \\
\text { 2010) }\end{array}$ & $\begin{array}{l}\text { A Hybrid Disciplined Agile } \\
\text { Software Process Model }\end{array}$ & Agile + Waterfall & $\begin{array}{l}\text { Scrum, Extreme Programming (XP), } \\
\text { Feature Driven Development (FDD) } \\
\text { and Rational Unified Process (RUP) }\end{array}$ & Software development \\
\hline $\begin{array}{c}\text { (Seyam \& } \\
\text { Galal-edeen, 2011) }\end{array}$ & Tragile & Agile + Waterfall & $\begin{array}{l}\text { SCRUM, XP, Crystal Family, } \\
\text { Structured Systems Analysis \& } \\
\text { Design Method (SSADM) }\end{array}$ & Information systems \\
\hline (Ambler, 2013) & Disciplined Agile Delivery & Agile + Agile & $\begin{array}{c}\text { XP, SCRUM, Lean Software } \\
\text { Development }\end{array}$ & Software development \\
\hline (Anitha et al., 2013) & V-model +Scrum & Agile + Waterfall & V-model, Scrum & Information systems \\
\hline (Binder et al., 2014) & Cocktail Model & Agile + Waterfall & Agile practices and ISO 21500 & Software development \\
\hline $\begin{array}{c}\text { (Ahmad et al., } \\
2014)\end{array}$ & XSR Model & Agile + Waterfall & $\begin{array}{c}\text { SCRUM, Extreme programming (XP) } \\
\text { and Rational Unified Process (RUP) }\end{array}$ & Software development \\
\hline (Cooper, 2014) & Agile-Stage-Gate & Agile + Waterfall & Stage-Gate ${ }^{\circledR}$ and agile practices & Complex projects \\
\hline $\begin{array}{c}\text { (Sommer et al., } \\
2015)\end{array}$ & Industrial Scrum Framework & Agile + Waterfall & Modelo Stage-Gate ${ }^{\circledR}$ and SCRUM & $\begin{array}{c}\text { Industry (wind turbines, } \\
\text { valves and sensors) }\end{array}$ \\
\hline (Silva, 2015) & Combined time planning & Agile + Waterfall & SCRUM and waterfall practices & Aircraft industry \\
\hline $\begin{array}{c}\text { (Conforto \& } \\
\text { Amaral, 2016) }\end{array}$ & $\begin{array}{l}\text { Iterative and Visual Project } \\
\text { Management Method }\end{array}$ & Agile + Waterfall & Stage-Gate ${ }^{\circledR}$ and agile practices & $\begin{array}{l}\text { Manufactured products } \\
\text { and software development }\end{array}$ \\
\hline
\end{tabular}

Table 2. Characteristics and problems of current hybrid management models. Source: The characteristics were based on the work of Conforto et al. (2015).

\begin{tabular}{|l|l|}
\hline \multicolumn{1}{|c|}{ Characteristics (C) } & \multicolumn{1}{|c|}{ Problems (P) } \\
\hline $\begin{array}{l}\text { C1. Combine principles, practices, techniques and tools from two } \\
\text { or more approaches; }\end{array}$ & $\begin{array}{l}\text { P1. Developed for specific contexts and should not be generalized for } \\
\text { any type of project; }\end{array}$ \\
\hline C2. Customized to meet project needs; & P2. Lack of a systematic procedure indicating how to combine practices; \\
\hline $\begin{array}{l}\text { C3. Balance predictability, anticipation and risk minimization } \\
\text { with flexibility; }\end{array}$ & $\begin{array}{l}\text { P3. Failure to consider internal and external factors in the decision process } \\
\text { for configuring hybrid models; }\end{array}$ \\
\hline $\begin{array}{l}\text { C4. Eliminates activities and documentation that do not add value } \\
\text { to project management; }\end{array}$ & $\begin{array}{l}\text { P4. There is no recommended practice for different projects and sectors } \\
\text { of the economy; }\end{array}$ \\
\hline $\begin{array}{l}\text { C5. Can present different roles and responsibilities by working } \\
\text { collaboratively; }\end{array}$ & P5. Absence of performance analysis of the selected practices; \\
\hline \multirow{2}{*}{ C6. Combine process discipline with team self-management. } & $\begin{array}{l}\text { P6. The proposals do not consider the association of risks by type of } \\
\text { project; }\end{array}$ \\
\cline { 2 - 2 } & P7. There is no association of problems or lessons learned with practices. \\
\hline
\end{tabular}


Conforto et al. (2011) was used. The research steps can be seen in Table 3.

The following strings and Boolean operators were used: "Association Rules" or "Association analysis" or "Apriori Algorithm" AND Project* or "Project management" or "Project assessment" or "Agile" or "Plan-driven" or "warterfall". It was necessary to exclude results that focused on the health area, since many studies related to medicine and diagnosis use the association rules technique.

Three criteria were used to guide the selection process: I) The studies had to discuss applications of association rules in the area of project management; II) Present proposals to improve the project management process; and III) Relate the use of association rules to develop management models. Next, we present the main studies that explore the use of association rules for project management and discuss their relationship with the research objective.

\section{Results and discussion}

The increasing restrictions (e.g. time, cost, quality) and complexity of the projects, combined with the advancement of technologies has contributed to the advancement of research in this area. Data mining is a possible solution to contribute to the effective management of projects in this new business environment. Several authors have studied the use of data mining techniques in the area of project management.

Chawla et al. (2003) used association rules networks (ARNs) in conjunction with cluster analysis to discover patterns that characterized the success or failure of Open Source Software (OSS) projects, so that new projects could benefit from the knowledge produced. However, the authors

Table 3. The research method.

\begin{tabular}{|c|l|}
\hline Step & \multicolumn{1}{|c|}{ Description } \\
\hline Step 1 & $\begin{array}{l}\text { Initially we defined the research problem, the objective } \\
\text { of SLR, the inclusion criteria, the primary sources of } \\
\text { information, the search strings and the SLR schedule. }\end{array}$ \\
\hline Step 2 & $\begin{array}{l}\text { The searches were performed in the pre-established } \\
\text { databases (Web of Science } \\
\text { the search strings defined in the previous step. A total of } \\
\text { 1101 articles were found. }\end{array}$ \\
\hline Step 3 & $\begin{array}{l}\text { The results went through three selection filters. In the first } \\
\text { filter, the title, summary and keywords were read, which } \\
\text { should be in agreement with the pre-established criteria, } \\
\text { culminating in the selection of 50 papers. In the second } \\
\text { filter, the introduction and conclusion of these articles } \\
\text { were read, and 15 papers were selected for the next filter. } \\
\text { The third filter consisted of a complete analysis of the } \\
\text { documents. At the end of the process, 11 papers were } \\
\text { selected. }\end{array}$ \\
\hline Step 4 & $\begin{array}{l}\text { The selected articles were cataloged and stored in a } \\
\text { repository. }\end{array}$ \\
\hline Step 5 & The articles were analyzed and the results were synthesized. \\
\hline
\end{tabular}

do not explain and do not discuss the importance and impact of the rules for project management.

Veloso (2003) discusses the use of association rules applied in the planning of human resources, assisting in the formation of the project team. This activity is complex and deals with several variables: technical and personal characteristics of human resources, availability, project and customer characteristics, among others (Veloso, 2003). According to the author, the association rules can generate results such as: if A works on a given project, then B has $\mathrm{x} \%$ probability of working on that same project. The author generated his results from historical records of real project time reports developed by a given company, using the Apriori algorithm. However, some questions can be better explored: how to feed the database with new resources, which do not yet have experience in the organization? Can the unit of analysis be phases or activities of the project? In addition to the time reports, are there other ways to collect the data? Is it possible to recommend changes to a project already under development? Despite this, the work brings interesting contributions to the area of project management, allowing professionals to have a technique capable of supporting them in choosing human resources for a project.

García et al. (2004a) propose a method to prioritize the strongest association rules to assist decision making in software projects without the need of domain knowledge. It is an iterative process that aims to refine the generated rules, selecting the most useful rules for the user. The authors exemplify the process for estimating a project's effort. The authors' main focus is on the application of this refinement method and, consequently, they do not discuss how the results found (effort and project size) can effectively help the project manager in conducting their projects.

García et al. (2004b) use clustering and association rules algorithms to discover patterns that relate the size of a software project, with other attributes (lines of code), such as the effort required to complete it. After generating the rules, the authors present the same refinement method discussed in the previous paragraph. The study of the relationship between software size and measures of the final product such as lines of code is interesting because it allows analyzing information at the beginning of the project to assist in its planning. However, the authors do not show the impact of their analysis on a real project, nor do they address how the study can help other projects besides software development.

Song et al. (2006) integrate association rules with classification techniques to predict software defects and the efforts need to correct them, based on historical software engineering data. The proposal makes it possible to understand how a defect relates to another, allowing the project manager to make decisions and avoid future defects or problems. With the proposed method, the authors also discuss about effort prediction rules, which can also help 
professionals in this field. Other studies can explore the proposed method to analyze multiple databases and help professionals to identify the main defects by type of project and the effort required.

García et al. (2008) mined project data using association rules to estimate the influence of certain management policy factors on various attributes of the software project such as technological, product and process factors. As a result, the authors present eleven rules associating the impact of management policies with the quality, time and effort of software development. The authors' focus is on testing and analyzing the proposed method, without thoroughly discussing the generated rules and the implication of such patterns in the area of project management.

Prasad et al. (2010) explore the factors that guide the project to success using data mining tools such as association rules (Apriori), decision tree, neural networks and Naive Bayes. The database was formed through an online survey, analyzing success and failure factors, in addition to verifying whether the respondent's project was a success or not. The authors' idea is pertinent, but no concrete results are shown of what are the factors that actually lead to the success of a project and / or how we could change the progress of a project towards success based on the results found. New studies can be carried out with the same objective in more robust databases in order to generate results that objectively assist professionals in project management.

Azzeh et al. (2010) use association rules in conjunction with "Fuzzy set theory" to predict the effort required for a given stage of the project based on information from previous stages, in order to avoid that the initial plan has a large difference from the end. The aim is to allow the project manager to reallocate the correct number of resources, reschedule the project and track the project's progress to finish on time and within budget (Azzeh et al., 2010). The work is strongly based on quantitative analysis, however the results found are not converted into tangible information to assist professionals in the development of their projects. We conclude that the main contribution of the study is in the combination of association rules and "Fuzy set theory" that can be used for other purposes.

Emanuel et al. (2010) as well as other studies, used the association rules to find the success factors of Open Source Software Projects (OSS). For the authors, the project is considered a success based on the number of downloads on the platform (sourceforge.net). The work resulted in six factors that should be used in projects of this type to increase their success: the project must target ordinary users as an audience, the source code must be in production / stable, must work on both the Linux and Windows operating systems, must be reviewed by at least one user, have a file name in zip format with size in megabyte, and the project must have an English translation. The study achieves its objective, but some doubts arise: Is the number of downloads a good metric for the success of a project? Are the practices adequate to the project needs? Does the management model impact the success of the project? Future studies can explore these issues.

Parsanejad (2013) uses the association rules to discover the relationship between nine project success criteria, which were identified through a literature review containing 170 studies. The criteria used are: Cost, Time, Quality, Owner/Sponsor Satisfaction, Organization Satisfaction, Project Team Satisfaction, Supplier Satisfaction, Customer Satisfaction, and Stakeholder Satisfaction. This work is different from the previous ones, because it explores the impact of the results for project management, assisting professionals in the conduct of their projects. Future research can specifically study each of the relationships addressed, in order to validate the results and expand the discussion on the topic.

Savchuk et al. (2017) investigated the use of association rules in order to predict the time needed to correct a certain error in software development, through the relationship between bugs and time, in addition to being able to predict the professional who will correct this error according to their skills. The basic idea is to find similar cases in previous situations, analyze them and use this knowledge and information for new challenges (Savchuk et al., 2017). Despite the proposal, the authors do not show any association rules, focusing only on the amount of results found in relation to the number of bugs in the analyzed data. A discussion was expected between the association between the bugs and the effort required to resolve them.

The majority of the studies presented focus on the application of mathematical models, without assessing the impact of techniques and methods on the performance of project management, not exploring in depth how to effectively assist the organization or professionals in conducting their projects. The focus on the use of mathematical models is not a bad thing, but the direct implications for project management could be better explored. Another aspect to be highlighted is the domain of software development among the studies. Despite the limitations, the authors agree on the potential use of data mining techniques to improve and assist in the evolution of project management, presenting proposals to allocate resources, estimate effort and time to collect a project activity, or identify the success factors of a project.

\subsection{Association rules and hybrid models}

Based on the work discussed in the previous section and the opportunities (potential use) of the association rules technique to assist in the use of hybrid models to manage complex projects in dynamic environments, we 
present proposals for the application of data mining to help solve the problems related to hybrid models (see Table 1 - Section 2.2).

\section{- P1. Developed for specific contexts and should not} be generalized for any type of project. The practices of a hybrid model need to be customized for specific contexts, without generalization for all types of projects in the organization. Each project is unique and must be managed in different ways. The hybrid models in the literature were developed based on this principle, however they are prescriptive models to be used by other organizations and professionals. For these models to work outside the context for which they were created, companies need to make changes in several areas, such as teams, processes, organizational structure, governance, which makes the use of these models difficult. At the same time, there is a lack of methods and tools capable of assisting organizations in developing solutions that are aligned with the reality they face. Data mining, specifically the association rules, can help organizations and professionals to identify, from the results of their previous projects, which management practices are best suited for use in their own context and type of project and which need to be reviewed. In this way organizations can use past experience and be inspired by existing hybrid models to create the best solution for their case;

- P2. Lack of a systematic procedure indicating how to combine practices, and P4. There is no recommended practice for different projects and sectors of the economy. Association rules has the potential to analyze large volumes of project data and use algorithms to relate management practices to the organizational environment, characteristics of a project, and level of agility, in order to recommend an appropriate management model for each situation. The use of the association rules technique will not increase the agility of the organization's projects by itself, however the information generated through the analysis of the rules can contribute to the use of management practices that are more aligned with the characteristics of a project and organizational factors, favoring the development of agility for that project. For example, we could have rules such as: Practice (x) AND Environment (y) $\Rightarrow$ Agility (z). Thus, a procedure can be developed to generate combinations of management practices in an automated way, being able to identify the practices most aligned with the organization and its projects, eliminating the need for a project management specialist;
- P3. Failure to consider internal and external factors into the decision process for hybrid models configuration. This problem should be further investigated using appropriate data modeling and correlation techniques. Future research may use data mining to identify internal and external factors to the organization that impact the choice of practices to create the hybrid model and its use in the organization's projects;

\section{- P5. Absence of performance analysis of the selected} practices. We can analyze the data related to the results obtained with the practices used in past projects, and compare them with the results achieved with the new practices/management models. Here we also have another opportunity for discussion. In traditional management, methods such as Earned Value Analysis are applied to monitor the evolution of the project. In the hybrid environment we can include agile teams as responsible for deliveries. Would it be possible to use mining techniques to combine data from agile teams in hybrid projects and associate them with value indicators? This question may open up new research opportunities to develop retrofit models to continue improve the decision process;

- P6. The proposals do not consider the association of risks by type of project. Organizations can use association rules to associate potential risks according to the type of project, enabling more consistent risk management that can be used in future projects;

- P7. There is no association of problems or lessons learned with practices. Association rules and other datamining techniques can be used to generate a list of practices used in previous projects, the problems faced and how they were overcome, summarizing the lessons learned to be used in future projects and assisting project teams.

\section{Conclusion}

Hybrid models have proven to be interesting in dealing with the complexity of the new business environment. The combination of practices aligned with the organizational environment allows to customize the management model to the reality of each project. However, a series of problems arise in this scenario, such as finding the best combination for each situation.

The present study explored the potential use of data mining in project management to assist in solving some of these problems. Among the data mining techniques, the one that best suited the objectives of this study are the 
association rules, which allow the identification of frequent patterns, associations and correlations in large data sets. Through a literature review we identified studies that used association rules to assist in project management, whether to assist in choosing resources to form the project team, to discover the effort required to complete the project or parts of it, and to predict bugs in software and the efforts required to fix them.

Based on these results, we propose some solutions to the problems related to the application of hybrid models. The problems of combining practices seem to be the most promising for the use of data mining techniques. Seven problems were addressed to assist companies and professionals in choosing and combining the most appropriate practices for their projects according to their specificities.

Regarding the limitations, the proposals to solve the problems evidenced by hybrid models have not been validated. Future research can study the use of data mining for each of the mentioned problems, opening up new research opportunities. For example, new algorithms can be developed and incorporated into project management information systems in order to extract important information to assist organizations and professionals in conducting their projects (e.g. information related to performance, practices, resources, risk, communication). Another opportunity may be the development / use of data extraction, integration and analysis techniques, allowing the creation of a project management database and subsequent generation of new knowledge.

Advances in data analysis can bring benefits to project management, generating the opportunity to assist organizations and professionals in decision making and in the development of new management solutions more aligned with the needs and objectives of their projects.

\section{Acknowledgements}

This work was supported by the Coordenação de Aperfeiçoamento de Pessoal de Nível Superior - Brasil (CAPES) - Finance Code 001, without which it would not be possible to carry out this work.

\section{References}

Adelakun, O., Garcia, R., Tabaka, T., \& Garcia, R. (2017). Hybrid project management : agile with discipline. In International Conference on Information Resources Management (CONF-IRM). Atlanta: Association For Information Systems.

Ahmad, G., Soomro, T., \& Brohi, M. (2014). XSR: Novel Hybrid Software Development Model (Integrating XP, Scrum \& RUP). International Journal of Soft Computing and Engineering, 3, 126-130. Retrieved in 2020, November
15, from http://www.ijsce.org/attachments/File/v4i2/ B2228054214.pdf

Alqudah, M., \& Razali, R. (2016). A Review of Scaling Agile Methods in Large Software Development. International Journal on Advanced Science. Engineering and Information Technology, 6(6), 828-837. http://dx.doi.org/10.18517/ ijaseit.6.6.1374.

Ambler, S. W. (2013). Going beyond scrum: disciplined agile delivery (White Paper Series, pp. 1-16). USA: Disciplined Agile, Inc.

Ambler, S., \& Lines, M. (2018). Choose your WoW! A disciplined agile delivery handbook for optimizing your way of working. USA: Disciplined Agile, Inc.

Anitha, P. C., Savio, D., \& Mani, V. S. (2013). Managing requirements volatility while 'Scrumming' within the V-model. In Proceedings of the 3rd International Workshop on Empirical Requirements Engineering (EmpiRE) (pp. 17-23). USA: IEEE. https://doi.org/10.1109/ EmpiRE.2013.6615211.

Azzeh, M., Cowling, P. I., \& Neagu, D. (2010). Software stageeffort estimation based on association rule mining and fuzzy set theory. In Proceedings of the 10th IEEE International Conference on Computer and Information Technology (pp. 249-256). USA: IEEE. https://doi.org/10.1109/CIT.2010.76.

Binder, J., Aillaud, L. I., \& Schilli, L. (2014). The project management cocktail model: an approach for balancing agile and ISO 21500. Procedia: Social and Behavioral Sciences, 119(119), 182-191. http://dx.doi.org/10.1016/j. sbspro.2014.03.022.

Chawla, S., Arunasalam, B., \& Davis, J. (2003). Mining open source software (oss) data using association rules network. Advances in Knowledge Discovery and Data Mining (pp. 564-564). USA: Springer. Retrieved in 2020, November 15, from http://www.springerlink.com/ index/6DVYCHN9DVMPHEAT.pdf

Cho, J. (2009). A hybrid software development method for large-scale projects: rational unified process with scrum. Issues in Information Systems, 10(2), 340-348. Retrieved in 2020, November 15, from http://iacis.org/iis/2009/ P2009_1267.pdf

Cios, K. J., Pedrycz, W., Swiniarski, R. W., \& Kurgan, L. A. (2007). Data mining a knowledge discovery approach. USA: Springer Science \& Business Media.

Ciric, D., Lalic, B., Gracanin, D., Palcic, I., \& Zivlak, N. (2018). Agile project management in new product development and innovation processes : challenges and benefits beyond software domain. In: Proceedings of the 2018 IEEE International Symposium on Innovation and Entrepreneurship (TEMS-ISIE) (pp. 1-9). USA: IEEE. 
Conforto, E. C., \& Amaral, D. C. (2016). Journal of Engineering and Technology Agile project management and stage-gate model: a hybrid framework for technologybased companies. Journal of Engineering and Technology Management, 40, 1-14. http://dx.doi.org/10.1016/j. jengtecman.2016.02.003.

Conforto, E. C., Amaral, D. C., \& Da Silva, S. L. (2011). Roteiro para revisão bibliográfica sistemática : aplicação no desenvolvimento de produtos e gerenciamento de projetos. In Anais do $8^{\circ}$ Congresso Brasileiro de Gestão de Desenvolviemnto de Produto (pp. 1-12). Porto Alegre: UFRGS. Retrieved in 2020, November 15, from http://www. ufrgs.br/cbgdp2011/downloads/9149.pdf

Conforto, E., Barreto, F., Amaral, D., \& Rebentisch, E. (2015). Modelos híbridos unindo complexidade, agilidade e inovação. Revista Mundo PM, 64, 10-17.

Cooper, R. G. (2014). What's next?: after Stage-Gate. Research Technology Management, 57(1), 20-31. http://dx.doi. org/10.5437/08956308X5606963.

Emanuel, A. W. R., Wardoyo, R., Istiyanto, J. E., \& Mustofa, K. (2010). Success factors of OSS projects from sourceforge using Datamining Association Rule. In Proceedings of the 2010 International Conference on Distributed Frameworks for Multimedia Applications (pp. 1-8). USA: IEEE.

Fitzgerald, B., Stol, K., Sullivan, R. O., \& Brien, D. O. (2013). Scaling agile methods to regulated environments: an industry case study. In Proceedings of the 35th International Conference on Software Engineering (ICSE). USA: IEEE.

Floricel, S., Piperca, S., \& Tee, R. (2018). Strategies for managing the structural and dynamic consequences of project complexity. Complexity, 2018:3190251.

García, M. N., Román, I. R., García Peñalvo, F. J., \& Bonilla, M. T. (2008). An association rule mining method for estimating the impact of project management policies on software quality, development time and effort. Expert Systems with Applications, 34(1), 522-529. http://dx.doi. org/10.1016/j.eswa.2006.09.022.

García, M., Peñalvo, F., \& Martín, M. (2004a). Mining interesting association rules for prediction in the software project management area. In Proceedings of the 2004 International Conference on Data Warehousing and Knowledge Discovery (pp. 341-350). USA: Springer. Retrieved in 2020, November 15, from http://www. springerlink.com/index/eak6h2buqtkwpq1p.pdf

García, M., Quintales, L., Peñalvo, F., \& Martín, M. (2004b). Building knowledge discovery-driven models for decision support in project management. Decision Support Systems, 38(2), 305-317. http://dx.doi.org/10.1016/S01679236(03)00100-3.
Han, J., Kamber, M., \& Pei, J. (2012). Data mining: concepts and techniques. San Francisco: Morgan Kaufmann. https:// doi.org/10.1016/B978-0-12-381479-1.00001-0.

Hobbs, B., \& Petit, Y. (2017). Agile methods on large projects in large organizations. Project Management Journal, 48(3), 3-19. http://dx.doi.org/10.1177/875697281704800301.

Houtsma, M., \& Swami, A. (1995). Set-oriented mining for association rules in relational databases. In Proceedings of the 11th International Conference on Data Engineering (pp. 25-33). USA: IEEE. https://doi.org/10.1109/ ICDE.1995.380413.

Iansiti, M., \& Lakhani, K. R. (2014). How connections, sensors, and data are revolutionizing business. Harvard Business Review, 92(11), 19.

Imani, T., Nakano, M., \& Anantatmula, V. (2017). Does a hybrid approach of agile and plan-driven methods work better for IT system development projects? International Journal of Engineering Research and Applications, 7(3), 39-46. http://dx.doi.org/10.9790/9622-0703043946.

Luo, L., He, Q., Jaselskis, E. J., Asce, A. M., \& Xie, J. (2017). Construction project complexity. Research Trends and Implications, 143(7), http://dx.doi.org/10.1061/(ASCE) CO.1943-7862.0001306.

Nawrocki, J., Olek, L., Jasinski, M., Paliświat, B., Walter, B., Pietrzak, B., \& Godek, P. (2006). Balancing agility and discipline with XPrince. Lecture Notes in Computer Science, 3943, 266-277. http://dx.doi.org/10.1007/11751113_19.

Parsanejad, M. (2013). Applying association rules to explore relationships among project success criteria. Journal of Industrial and Intelligent Information, 1(2), 77-80. http:// dx.doi.org/10.12720/jiii.1.2.77-80.

Prasad, A., Arsiwala, J., \& Singh, P. P. (2010). Estimating and improving the probability of success of a software project by analysing the factors involved using data mining. In Proceedings of the 2010 International Conference on Artificial Intelligence and Education (Vol. 1, pp. 391-394). USA: IEEE. https://doi.org/10.1109/ICAIE.2010.5641159.

Rahimian, V., \& Ramsin, R. (2008). Designing an agile methodology for mobile software development: a hybrid method engineering approach. In Proceedings of the 2nd International Conference on Research Challenges in Information Science. USA: IEEE. https://doi.org/10.1109/ RCIS.2008.4632123.

Riesener, M., Dölle, C., Ays, J., \& Ays, J. L. (2018). Hybridization of development projects through processrelated combination of agile and plan-driven approaches. In Proceedings of the IEEE International Conference on Industrial Engineering and Engineering Management (IEEM) (pp. 602-606). USA: IEEE. 
San Cristóbal, J. R., Diaz, E., Carral, L., Fraguela, J. A., \& Iglesias, G. (2019). Complexity and project management : challenges, opportunities, and future research. Complexity, 2019, 6979721.

Savchuk, T. O., Pryimak, N. V., Assembay, A., Zyska, T., Junisbekov, M., \& Annabaev, A. (2017). The technology of searching the associative rules while developing the software. Photonics Applications in Astronomy, Communications, Industry, and High Energy Physics Experiments, 10445, 104451Y. http://dx.doi.org/10.1117/12.2280900.

Seyam, M. S., \& Galal-edeen, G. H. (2011). Traditional versus agile : the tragile framework for information systems development. International Journal of Software Engineering, 4(1), 63-93.

Silva, F. B. (2015). Proposta e avaliação de um procedimento de planejamento de tempo combinado ágil e tradicional [Dissertação de mestrado]. Escola de Engenharia de São Carlos, Universidade de São Paulo, São Carlos.

Silva, F. B., Bianchi, M. J., \& Amaral, D. C. (2019). Evaluating combined project management models: strategies for agile and plan-driven integration. Product: Management
\& Development, 17(1), 15-30. http://dx.doi.org/10.4322/ pmd.2019.003.

Sommer, A. F., Hedegaard, C., Dukovska-Popovska, I., \& Steger-Jensen, K. (2015). Improved product development performance through agile/stage-gate hybrids: the next-generation stage-gate process? Journal ResearchTechnology Management, 58(1), 34-45. https://doi. org/10.5437/08956308X5801236.

Song, Q., Shepperd, M., Cartwright, M., \& Mair, C. (2006). Software defect association mining and defect correction effort prediction. IEEE Transactions on Software Engineering, 32(2), 69-82. http://dx.doi.org/10.1109/ TSE.2006.1599417.

Veloso, M. J. S. A. (2003). Regras de associação aplicadas a um método de apoio ao planejamento de recursos humanos. Porto: Universidade do Porto.

Zaki, K. M., \& Moawad, R. (2010). A hybrid disciplined agile software process model. In Proceedings of the 7 th International Conference on Informatics and Systems (INFOS). USA: IEEE. 